\title{
Talking about the Application of High-tech Elements in the Innovative Design of Daily-use Ceramics
}

Fei Yu ${ }^{\text {a }}$

The department of art and design, Jingdezhen University, Jingdezhen, Jiangxi, China

\begin{abstract}
The relationship between technology and design is an eternal discussion as well as controversial topic. In the innovative design of daily-use ceramics, the advancement of technology has brought a lot of room for development in this field. This article will elaborate some effective combination of high-tech technology in daily-use ceramic design in the following four aspects: the combination of electronic technology and daily-use ceramics; the application of double-layer thermal insulation ceramics in the molding process; the analysis of the application of materials such as temperature-sensitive inks and the intervention of new healthy elements such as biochemical materials in the processing technology and surface treatment. Through these aspects to explore the current breakthrough in the design of daily-use ceramics.
\end{abstract}

\section{The effective combination of electronic technology and innovative design of daily-use ceramics}

In terms of molding process, one of the most prominent manifestations in recent years is the combination of various materials and ceramic materials. This will result in a variety of different process molding methods appearing in the design of daily-use ceramics, moreover, it has become a new design highlight that the combinative design of electronic technology and ceramic materials. There are three cases to illustrate the successful application of this aspect. The first one is the design of the ceramic heating cup in Figure 1, which consists of a cup body, a heating device and a bottom case. It is characterized in that: the bottom of the cup body is convex, the heating device is connected by a coil, an electronic temperature controller and a power connector, the electronic temperature controller is fixed at the bottom of the cup body, and the coil enwinds around the cup body protruding at the bottom to form a heating coil, the power connector is fixed on the bottom case, and the bottom case covers the bottom of the cup body and the heating device. The electric heating ceramic cup can be directly connected to the USB interface of computers or the vehicle power supply, as well as can be suitable for use in office and automobile.

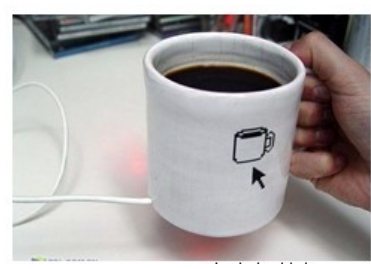

Figure 1 USB ceramic heating cup

The successful design of another case is the combinative design of the $\mathrm{CD}$ player and the coffee cup in the picture. The coffee cup is as the knob part of the $\mathrm{CD}$ player, which has both aesthetic and practical dual effects. It's a blessing to enjoy your favorite concert while enjoying the wonderful taste of coffee! (Figure 2)

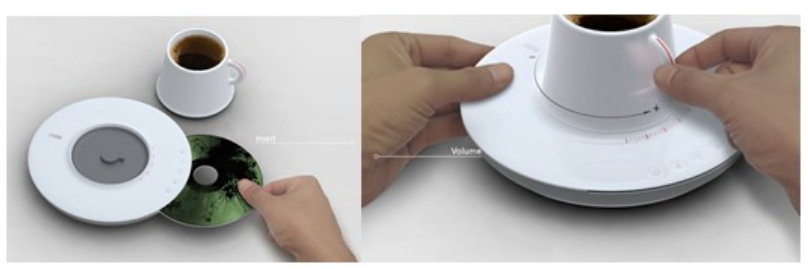

Figure 2 CD coffee cup

The cup in Figure 3 is a perfect combination of electronic components and ceramic design. It is a lightemitting cup with an inductive switch design. This cup is illuminated by an energy-saving LED light. If it is not touched for a long time, the light itself goes out. Such a cup is very suitable for using in places where lighting is not sufficient. You can imagine this kind of induction lighting design, using in other varieties of daily-use ceramics can also inspire some new ideas of designers, 
giving users a sense of freshness and at the same time, it is suitable for modern people to seek the idea of stimulating life!

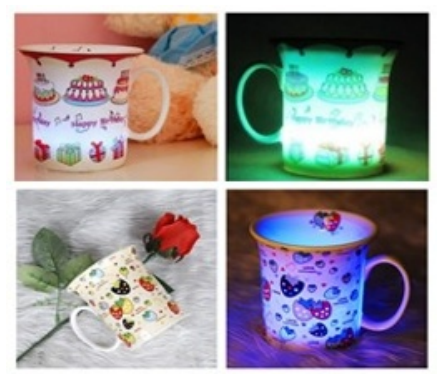

Figure 3 Untouched effect and Light effect after touch

\section{Improvements in the molding process have promoted more innovations in the combination of beauty and function of daily-use ceramics}

In the past, the ceramic cup has always maintained its own thin appearance, while now there are some new technological trends in the design of the cup. For example, it is an unique and novel design that the insulated. ceramic cup in Figure 4, which breaking through the traditional ceramic pattern, integrating daily use and functional art. Also, it caters to the aesthetic values of modern people. Its inner tank is filled with new nano ceramic materials, which are fired at high temperature. It is high technology, and has various compound functions, great thermal stability (180 degrees -- 20 degrees heat exchange without cracking). The shell is a fully transparent pc material (commonly known as space glass). It has many functions such as high strength, good toughness, difficult breaking, playing a role in protection, decoration, heat insulation, relative insulation and so forth.

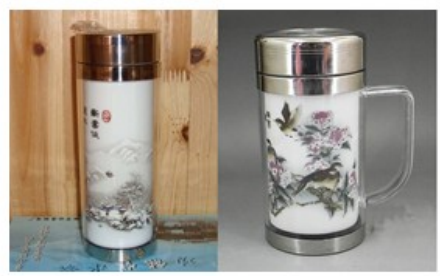

Figure 4 Ceramic cup

The PANTON insulation cup is a premium quality mug with a combination of aesthetics and craftsmanship (Figure 5). One-time compression molding, the doublelayered cup body forms a hollow heat-insulating area in the middle, which has the function of heat preservation and anti-scalding. No matter whether it is cold juice or hot tea in the cup, it will not make the hand holding the cup feel too cold or too hot. When using it to fill cold drinks, it is not easy to produce water drops on the outer edge of the cup which always drip wet the tabletop.

The PANTON insulation cup is a premium quality mug with a combination of aesthetics and craftsmanship (Figure 5). One-time compression molding, the double- layered cup body forms a hollow heat-insulating area in the middle, which has the function of heat preservation and anti-scalding. No matter whether it is cold juice or hot tea in the cup, it will not make the hand holding the cup feel too cold or too hot. When using it to fill cold drinks, it is not easy to produce water drops on the outer edge of the cup which always drip wet the tabletop.

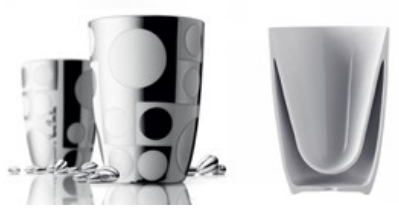

Figure 5 The picture of ceramic molding profile

Beautiful cup pattern from Geometry 1 designed by Verner Panton in 1960. The insulated cup is fired with high-quality porcelain clay at the high temperature of 1320 Celsius. With excellent strength and surface quality, this cup has won the accreditation of the FORM and DESIGN PLUS design awards for its superb design. One of the similar designs is a double-layer insulated green cup with the modern style produced by Starbucks in Figure 6. This double-layer cup also has a concept of environmental protection, which makes these portable double-layer ceramic cups replace the paper cups that were often used before, in order to reduce the pressure of the earth's pollution!

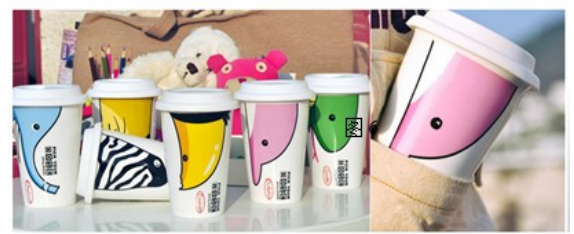

Figure 6 Ceramic cup

\section{In terms of external processing technology, the development of external materials has added new elements to the innovative design of daily-use ceramics}

\subsection{Application of temperature-changing ink materials on the surface decoration of daily-use ceramics}

In the past, the exterior decoration of daily-use ceramics' model was mostly based on flower paper design, while the material of flower paper can only show a constant appearance. However, nowadays, the application of temperature-changing ink materials has brought new improving room for the field of flower paper design (Figure 7). Temperature-changing ink, also known as thermochromic ink and changing color after meeting heat, is a special ink that can change color with temperature, because it undergoes physical changes (such as taking off crystal water, crystal structural interconversion, spatial configuration interconversion, etc.) or chemical changes (decomposition, compounding, oxidation, reduction, etc.), 
leading to changes in molecular structure and molecular morphology. As the result, it has an effect of color changing in appearance, which is classified into reversible achromatism, reversible coloration, reversible changing color, memory type, interval coloration, irreversible coloration and non-reversible color seven series. Anyone who can restore the original color of the pigment after the temperature drops is called the reversible thermochromic effect; otherwise it is called the irreversible thermochromic effect. Generally, a temperature-sensitive pigment can only produce one color, which is called a single thermochromic effect; when two or more temperature-sensitive pigments are used together, two or more colors can be produced during heating, which is called multi thermochromic effect (Figure 8).

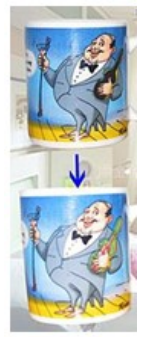

Figure 7 ceramic cup

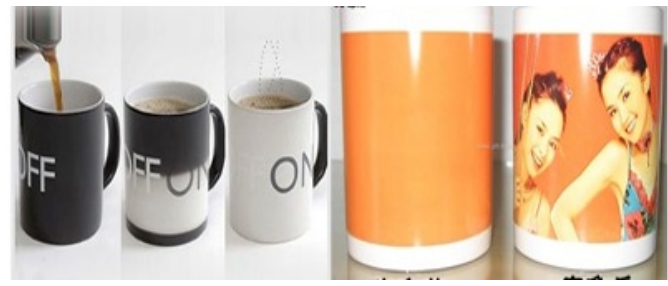

Figure 8 ceramic cup

\subsection{Application of electroplating silver and electroplating gold technology}

The application of electroplating technology glazing on the electroplating is bright no glazing, is matte electroplating, is the process of electroplating a thin layer of other metals or alloys on certain metal surfaces by using principle of electrolysis, is the process of attaching a metal film to the surface of metal or other material parts to prevent corrosion, improve wear resistance, electrical conductivity, light reflection, enhance aesthetics and other functions by using electrolysis effect (Figure 9).
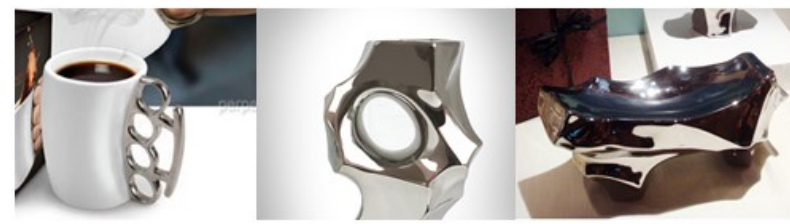

Figure 9 other functions ceramics

\section{Application of biochemical elements in the design of daily-use ceramics}

The 21 st century is a new century in which high-tech advances the world to develop. The world's ceramics and
Chinese ceramics in the new century didn't demonstrate the past features. At present, the problem of the amount of heavy metals such as lead and cadmium in daily-use porcelain has been basically solved. Most of the daily-use porcelains like decaling on glazes, coloring on glazes and coloring underglazes have achieved the requirements of non-toxic, durability and beauty. With the development of technology and the improvement of people's living standards, it is increasing that the requirements for improving the living environment, improving the quality of life and cherishing the health of the body. People have raised the basic functions of daily-use ceramics from aesthetics and using to a high requirement. Therefore, developing design and producing daily porcelain with the functions of antibacterial health care have a wide development potential.

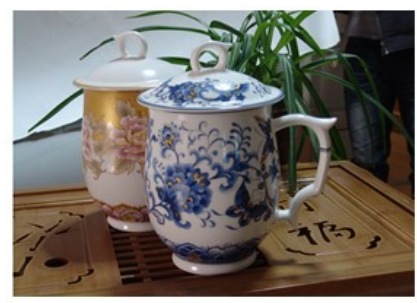

Figure 10 ceramic cup

Shows a new product in the past few years. The tourmaline bone china double-layer activated water health cup is a double-layer heat insulation applied by one-time grouting (in the same condition, it is increased 30\% than the ordinary tea cup on effect of heat preservation); at the same time, the tourmaline activation ball has the function of health care on the human body. Tourmaline is a natural crystal gemstone with unique piezoelectric effect and thermoelectric effect, which has various promoting effects on human health: it can improve human microcirculation by launching the far-infra red which the wavelength is 4-14 micrometers, called as "light of life" and matching with the far infrared wave of the human body; it can also release negative ions called as "air vitamins." The water is instantly activated by the tourmaline biochemical ceramic bead filter. Then the generated hydroxy anion can eliminate and neutralize oxygen free radicals in the body, play an antioxidant role. After drinking a long period of time, it can enhance immunity, delay aging, prevent cancer, prevent diabetes, cardiovascular and cerebrovascular diseases and other chronic, non-communicable diseases.

Of course, tourmaline is not the only type of biochemical materials, there are many materials such as medical stone and photocatalyst antibacterial agents, rare earth elements, silver antibacterial agents and so forth, which we can apply to the innovative design of daily-use ceramics. These healthy new ceramics will form a new trend in the innovative design of daily-use ceramics.

From the above analysis of the four points, we can see that the innovations of daily-use ceramic design are endless, and the development of all aspects of technology has promoted the pace of daily-use ceramic design. The above four points are just some small parts in this big ocean. The design is to make our life better, and our 
designers are slowly tasting our wonderful life brought by new technologies and discovering more new creative ideas through after tasting, in order to create a new height point for our China in daily-use ceramic design in international status.

\section{References}

1. Yang Yongshan. Ceramic Model Design [M]. Shenyang: Liaoning Science and Technology Press, 1988
2. Wang Xiaomu. Ceramic Technology [M]. Beijing: Light Industry Press, 1995

3. $\mathrm{Xu}$ Kaiqiang. Product Semantics - A Beautiful Interpretation of Design [J]. Packaging and Design, 1999, (1): 84 - 86

4. Wang Jianzhong. International Ceramic Design Grand View [M]. Beijing: Beijing Arts and Crafts Press, 1991. 